\section{(6) OPEN ACCESS}

\title{
Evolution of cost structures in rheumatoid arthritis over the past decade
}

\author{
Dörte Huscher, ${ }^{1,2}$ Thomas Mittendorf, ${ }^{3}$ Ulrich von Hinüber, ${ }^{4}$ Ina Kötter, ${ }^{5}$ \\ Guido Hoese, ${ }^{6}$ Andrea Pfäfflin, ${ }^{1}$ Sascha Bischoff, ${ }^{1}$ Angela Zink, ${ }^{1,2}$ for the German \\ Collaborative Arthritis Centres
}

\begin{abstract}
Handling editor Tore K Kvien
- Additional material is published online only. To view please visit the journal online (http://dx.doi.org/10.1136/ annrheumdis-2013-204311).

${ }^{1}$ Epidemiology Unit, German Rheumatism Research Centre, A Leibniz Institute, Berlin, Germany

${ }^{2}$ Department of Rheumatology and Clinical Immunology, Charité University Hospital, Berlin, Germany

${ }^{3}$ Herescon GmbH, Health Economic Research \& Consulting, Hannover, Germany

${ }^{4}$ Rheumatologist in Private Practice, Hildesheim, Germany ${ }^{5}$ Department of Rheumatology, Robert-Bosch Hospital, Stuttgart, Germany ${ }^{6}$ Rheumatologist in Private Practice, Stadthagen, Germany
\end{abstract}

\section{Correspondence to} Dörte Huscher, Epidemiology Unit, German Rheumatism Research Centre Berlin, A Leibniz Institute, Charitéplatz 1, Berlin 10117, Germany; huscher@drfz.de

Received 23 July 2013 Revised 7 November 2013 Accepted 10 December 2013 Published Online First 9 January 2014
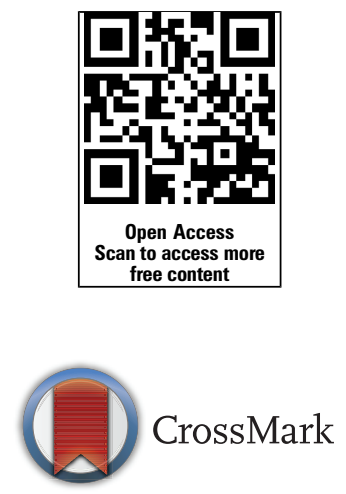

To cite: Huscher $D$, Mittendorf T, von Hinüber U, et al. Ann Rheum Dis 2015;74:738-745.

\section{ABSTRACT}

Objective To estimate the changes in direct and indirect costs induced by patients with rheumatoid arthritis (RA) in German rheumatology, between 2002 and 2011. To examine the impact of functional status on various cost domains. To compare the direct costs incurred by patients at working age (18-64 years) to patients at an age of retirement ( $\geq 65$ years).

Methods We analysed data from the National Database of the German Collaborative Arthritis Centres with about 3400 patients each year. Costs were calculated using fixed prices as well as annually updated cost factors. Indirect costs were calculated using the human capital as well as the friction cost approaches. Results There was a considerable increase in direct costs: from $€ 4914$ to $€ 8206$ in patients aged 18-64, and from $€ 4100$ to $€ 6221$ in those aged $\geq 65$, attributable to increasing prescription of biologic agents (18-64 years from $5.6 \%$ to $31.2 \%, \geq 65$ years from $2.8 \%$ to $19.2 \%$ ). This was accompanied by decreasing inpatient treatment expenses and indirect costs due to sick leave and work disability. The total growth of cost, on average, was €2437-2981 for patients at working age, and $€ 2121$ for patients at retirement age. Conclusions The increase in treatment costs for RA over the last decade was associated with lower hospitalisation rates, better functional status and a lower incidence of work disability, offsetting a large proportion of risen drug costs. Since the rise in drug costs has manifested a plateau from 2009 onwards, no relevant further increase in total costs for patients with RA treated in German rheumatology is expected.

\section{INTRODUCTION}

Rheumatoid arthritis (RA) is a chronic inflammatory disease with a prevalence around 0.8 (range: 0.3-1.0) per 100 adults, and a peak in onset of disease between 55 years and 64 years of age. ${ }^{1-3} \mathrm{It}$ has a high societal impact due to treatment requirements and losses in productivity. Cost-of-illness studies in Europe and Northern America estimated $€ 4000-6000$ for healthcare expenditures per patient and year. ${ }^{4-6}$ In a representative US household survey from 2008, the median annual healthcare expenditures for RA were US $\$ 4677$ compared with US\$1229 in a non-RA control group. Adjusted for differences in patient characteristics and comorbidities, incremental costs for RA were US $\$ 20855^{5}$ In German rheumatology, treatment costs in 2002 were $€ 4737$ per patient and year. ${ }^{7}$
The growing use of biologic agents in daily rheumatological practice has led to a 3-fold to 6-fold increase in direct costs in various European countries. ${ }^{8} 9$ The changes in treatment patterns have been accompanied by a decrease in mean disease activity (DAS28), in hospitalisation, sick leave and work disability. ${ }^{10}$ Significant reductions in hospitalisation, outpatient physician care, nurse visits and physiotherapy were observed in Sweden between 2001 and 2010 in RA patients relative to the general population. ${ }^{11}$ A systematic review of 19 studies showed positive effects of biological agents on absenteeism and presenteeism. ${ }^{12}$ Since longstanding high disease activity, poor functional status and comorbidity are the main cost drivers in $\mathrm{RA},{ }^{13}{ }^{14}$ the objective of this study was to analyse how recent changes in treatment and outcomes are reflected in resource utilisation and societal cost.

In Germany, biologic therapies for the treatment of RA are almost exclusively prescribed by rheumatologists. The National Database of the Collaborative Arthritis Centres (NDB), monitoring routine care in rheumatology since 1993, gives a structured insight to patients in need of these therapies. We analysed annual cross-sectional data from 2002 to 2011 to evaluate resource use and indirect cost components since the introduction of biologic therapies.

\section{PATIENTS AND METHODS}

\section{Database}

We used data from outpatients fulfilling the 1987 American College of Rheumatology (ACR) criteria for $\mathrm{RA}^{15}$ who were enrolled in the NDB between 2002 and 2011. Consecutive patients seen in the participating clinics or practices were recorded once per year, either as new or as follow-up cases. Data monitoring, as well as checks for completeness and plausibility, were performed centrally. Of the 18 participating centres which can be considered representative of German rheumatology, ${ }^{10}$ four outpatient clinics and four rheumatologic practices continuously reported over the entire decade. Their data were included in the analysis. Physicians documented symptom onset, diagnosis, comorbid conditions, drug prescriptions, non-medicinal treatment (eg, physiotherapy), and the disease activity score based on 28 joints (DAS28-ESR). Patients reported the incidence and duration of hospitalisation, inpatient and outpatient rehabilitation, sick leave, retirement status including permanent work disability, and the number of physician visits. Patient-reported indicators of 
quality of life were pain, fatigue and global health (on numerical rating scales from 0 to 10 with 10 being the poorest value) and functional status, using the Hannover Functional Status Questionnaire $(\mathrm{FFbH})$. This 18-item scale with scores ranging from 0 to $100(100=$ full function) can be transformed into Health Assessment Questionnaire (HAQ) values. ${ }^{16}$ We report the HAQ values in the following. The NDB received study approval from the ethics committee of the Charité Universitätsmedizin Berlin (EA1/196/06).

\section{Cost components}

When calculating the development of direct costs over time, two different approaches can be taken: resource utilisation cost can be calculated with fixed prices, taken from the first or the last observed year; alternatively, actual costs or prices from each respective year can be applied to reflect changes in pricing. We followed both approaches in figure 1 to visualise the differences. In all analyses we used current prices.

Direct costs in the context of this paper are defined as expenses from the perspective of the statutory health insurance. Around $90 \%$ of the German population is covered under this health insurance system, with almost full coverage of all healthcare services, leaving only minimal copayments for patients.

In 2005, the documentation routine for disease-modifying anti-rheumatic drugs (DMARD) during the past 12 months was changed from a binary yes/no format to recording also start and stop dates, as well as dosages. We, therefore, imputed information on dosing and duration for DMARDs and glucocorticoids (GC) for 2002-2004 with the median values from the following years. Drug costs for DMARDs and GCs were calculated based on official prices for each individual year. ${ }^{17}$ Costs do not include the costs of administration.

For other concomitant drug therapies, such as non-selective NSAIDs, COX-2 inhibitors or antiosteoporotic drugs, information was available only in a yes/no format. Allowing for treatment start during the year and assuming a continuous intake due to the chronic disease thereafter, an average intake of 9 months with average dosages was used for calculation.

Patients reported on non-drug therapies, including physiotherapy, occupational therapy, and patient education, which they had received during the past 12 months through 2004. From 2005 onwards, this data was retrieved from the physician.

Imaging included X-rays of the hands, feet and spine, MRI, CT, sonography of the joints and osteodensitometry.

The average daily cost of inpatient rehabilitation was based on the annual statistics of the German Pension Insurance Funds. ${ }^{18}$ The hospitalisation costs were retrieved from the online database of the costs distribution of hospitals of the Federal Statistical Office. ${ }^{19} 20$

In line with current health economic guidelines, ${ }^{21}$ the cost for a day of sick leave or work disability was calculated as the gross income from dependent work divided by the number of persons employed in dependent work, which resulted in €95-99 per day. ${ }^{22}$ We have restricted considerations to costs due to absenteeism, since presenteeism and occupational changes could not be estimated with our data. However, capturing the number of absent days is relatively straightforward and uncontroversial, while measurement of presenteeism and unpaid work still lacks a clear measurement methodology. ${ }^{23} 24$

To evaluate indirect costs, a human capital (HCA), and also a friction cost approach (FCA) were used when calculating the

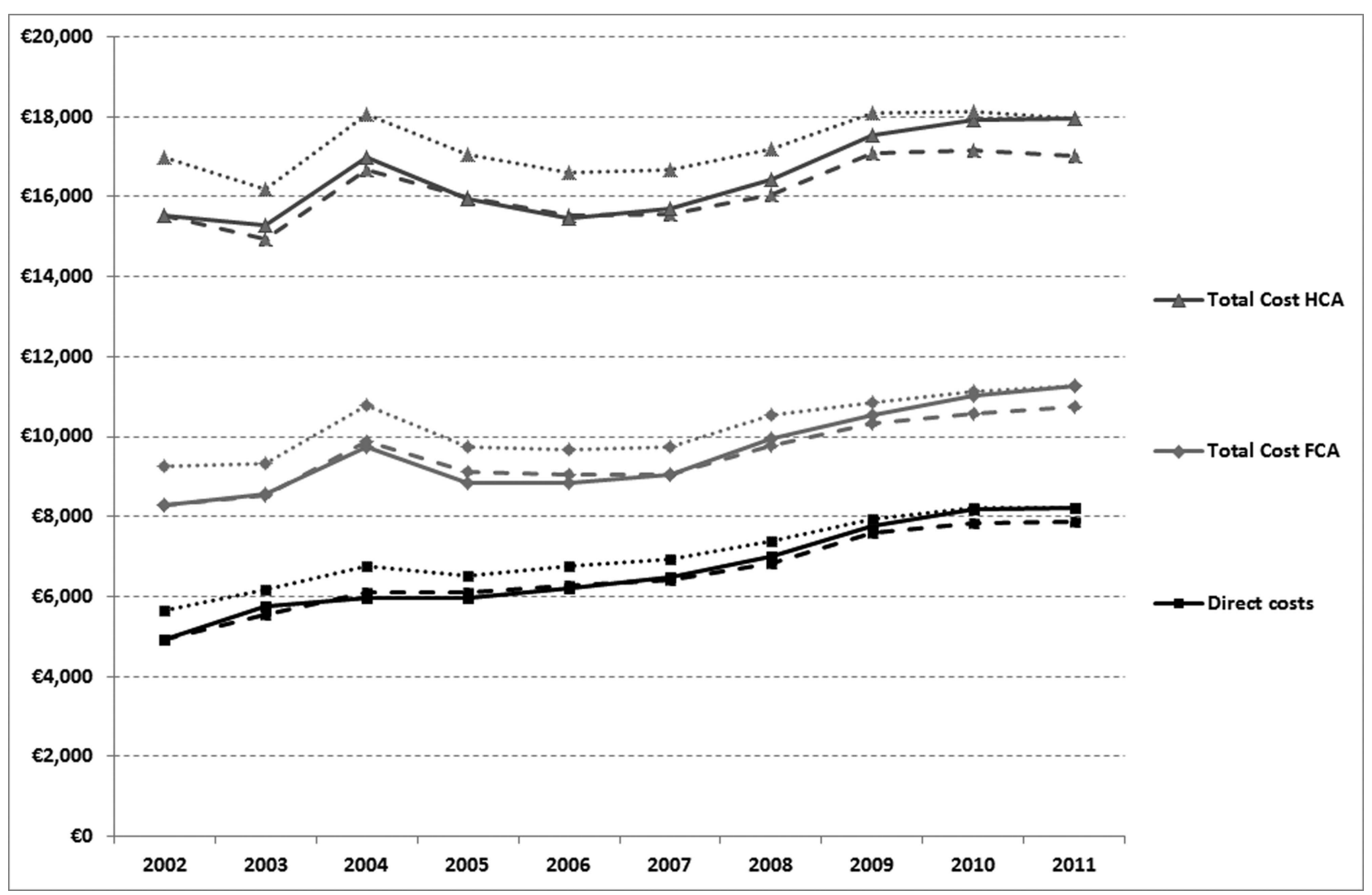

Figure 1 Cost development of direct and total costs with current prices (solid line), with fixed prices of 2002 (dashed line), and with fixed prices of 2011 (dotted line) for patients aged 18-64 years. 
cost of disability pensions. The HCA assumes that an individual resigning from employment due to permanent work disability will not be replaced until the regular retirement age. The FCA takes into account that an early retired employee is replaced within a certain period, ${ }^{22} 25$ in Germany 60-69 days in that decade (see online supplement $\mathrm{S} 1$ ).

The average annual costs were calculated for patients at working age (18-64 years), and for those in retirement age ( $\geq 65$ years). Furthermore, costs were compared in subgroups stratified by functional capacity.

\section{RESULTS}

Between 2902 and 4020 adult patients with RA could be included in the analyses for the years 2002-2011 (table 1). On average, patients were 62 years old with median disease duration of 9 years. The mean disease activity score (DAS28-erythrocyte sedimentation rate (ESR)) decreased from 3.9 to 3.5 over the course of the observation. This is in line with an increase of the proportion of patients with a low disease activity (DAS28<3.2), from $35 \%$ in 2002 to $46 \%$ in 2011 . Approximately half the patients were at working age with an average age of 52 years in that subgroup. The proportion of gainfully employed patients rose from $39 \%$ in 2002 to $53 \%$ in 2011 . The proportion of patients on disability pension decreased from $24.5 \%$ to $20.6 \%$. Despite the rising participation in the workforce, the proportion of patients with periods of sick leave during the past 12 months remained stable with about one-third of those gainfully employed, and the cumulative duration of sick leave episodes decreased from 60 days to 47 days for those with any disease absence. On average, the subpopulation in retirement was 73 years of age. There was no relevant difference in patientreported outcomes or disease activity between the younger and the older groups.

\section{Use of healthcare}

Healthcare usage, which comprises physician visits, medications, non-drug treatments and hospitalisation as well as inpatient rehabilitation, changed considerably between 2002 and 2011 (table 2). In the entire patient population, the proportion of patients being prescribed biologic DMARDs increased from 4\% in 2002 to $25 \%$ in 2011 , with $31 \%$ in the younger and $19 \%$ in the older population in 2011. Inpatient treatments decreased in frequency and duration, with a more pronounced decline in duration in the older group, and in both groups higher shortening compared to the age-matched and sex-matched general population. Imaging techniques were applied with a decreasing frequency, which can be attributed mainly to an $18 \%$ decline in X-rays of hands and feet.

\section{Cost development}

During the analysed decade, overall direct cost of patients aged $18-64$ years increased by $3292 €(+67 \%)$ (figure 1 ). When applying fixed prices of 2002 , the rise is somewhat lower $(€ 2951,+60 \%)$. It is the lowest when using fixed prices of $2011(€ 2552,+45 \%)$. Comparing total costs between 2002 and 2011, the increase is $€ 2981(+36 \%)$ with the FCA, and $€ 2437$ $(+16 \%)$ when using the HCA. With fixed prices from 2002, this is reduced to $€ 2448$ ( $+29 \%)$ for FCA and $€ 1481(+10 \%)$ for HCA. Applying fixed prices of 2011, the total cost increase is the lowest with $€ 2015$ (+22\%) for FCA, and $€ 983$ (+6\%) for HCA, respectively.

In agreement with changing prescription patterns, costs for drug treatment increased, regardless of whether patients were at working age or retired (table 3). The increase in cost for biologic DMARDs was $€ 3598$ for younger patients, and $€ 2265$ for older patients. In the same period, the average cost for synthetic DMARDs decreased by $€ 54$ and $€ 19$, respectively. Costs for other antirheumatic drugs, including steroids, non-selective and selective NSAIDs, as well as osteoporosis prophylaxis or treatment, increased by $€ 23-35$.

The increasing drug costs were accompanied by decreasing costs for inpatient treatment, with reductions of $€ 299$ for a younger patient, and $€ 429$ for a retired patient. For younger patients, two-thirds of these savings were generated by fewer treatments in acute care hospitals, and one-third by less inpatient rehabilitation. For older patients, three-quarters of the cost savings were attributable to treatment in acute care hospitals, and one-quarter to rehabilitation. Other costs remained roughly the same. In summary, between 2002 and 2011 , total direct costs increased by approximately $€ 3292$ for a patient at working age, and $€ 2121$ for a retired patient. Changes in cost shares for direct costs are illustrated in online supplement S2.

For patients at working age, the indirect costs of sick leave and permanent work disability form an important part of a patient's average annual costs from a societal perspective. Sick leave accounted for approximately $€ 1700$ per patient in 2002 , and decreased to $€ 1530$ in 2011 (table 3, upper part). The major indirect cost component is permanent work disability. When using the FCA, the share of permanent work disability was $€ 1680$ in 2002 , decreasing to $€ 1550$ in 2011 ; when using the HCA, costs decreased from $€ 8902$ to $€ 8229$. In summary, total indirect cost decreased by $€ 310$ (FCA) and $€ 855$ (HCA).

Accordingly, the overall total annual costs increased by approximately $€ 2981$ with the FCA, or $€ 2437$ with the HCA, for patients at working age with RA. Retired patients had an increase in annual costs of approximately $€ 2121$.

By analysing a subsample of patients with disease duration 210 years, we reduced the variability of proportions of patients with early or very long-standing disease between the years (see online supplement S3). For the group aged 18-64 years, total costs calculated with the HCA did not show a systematic increase or decrease over the past decade, whereas for retired patients, total costs increased by $€ 753$.

\section{Cost development by functional capacity}

Since we had seen an overall shift towards better functional capacity, we investigated if costs changed within strata of functional capacity. For patients at working age (figure 2), the direct costs increased in patients with poor function (HAQ $>2$ 3) from $€ 9374$ to $€ 11376$, in those with moderate disability (HAQ>1-2), from $€ 5498$ to $€ 11109$, in patients with mild disability (HAQ>0.5-1) from $€ 3573$ to $€ 6930$, and in those with good function $(\mathrm{HAQ} \leq 0.5)$ from $€ 2514$ to $€ 4473$. By contrast, using HCA, indirect costs were lower in 2011 than in 2002 for patients with mild disability ( $€ 5842$ compared to $€ 5393$ ), with good function (€2217 compared to $€ 1137)$, and with severe disability (€29 133 compared to $€ 26789$ ), whereas, there was an increase in those with moderate disability (from $€ 14375$ to $€ 15026$ ). When applying the FCA, a stronger decline was seen in the group with severe disability ($€ 3932$ ), and nearly no change in patients with good and moderate functional capacity $(-€ 338,-€ 94)$. Regarding total costs, a considerable increase was seen in the group with moderate disability (+€6063 FCA and +€6262 HCA), while there were smaller increases in the two better groups (FCA/HCA: + $€ 3263 /+€ 2908$ mild disability, $+€ 1621 /+€ 879$ good function) 
Table 1 Patient characteristics of cases analysed from 2002 to 2011

\begin{tabular}{|c|c|c|c|c|c|c|c|c|c|c|}
\hline & 2002 & 2003 & 2004 & 2005 & 2006 & 2007 & 2008 & 2009 & 2010 & 2011 \\
\hline \multicolumn{11}{|l|}{ All patients } \\
\hline Cases (n) & 3600 & 3857 & 4020 & 2902 & 3172 & 3301 & 3108 & 2958 & 3420 & 3327 \\
\hline Male (\%) & 20.9 & 20.7 & 21.2 & 23.4 & 24.3 & 24.3 & 25.1 & 24.8 & 25.3 & 24.2 \\
\hline Age $($ mean $\pm S D)$ & $61.2 \pm 12.4$ & $61.6 \pm 12.4$ & $61.9 \pm 12.4$ & $61.0 \pm 12.8$ & $61.7 \pm 12.9$ & $62.3 \pm 12.9$ & $62.5 \pm 12.9$ & $63.0 \pm 13.1$ & $63.6 \pm 13.1$ & $63.1 \pm 13.1$ \\
\hline Disease duration (median) & 8.0 & 8.2 & 8.4 & 8.2 & 8.7 & 9.2 & 9.0 & 9.7 & 10.2 & 10.3 \\
\hline DAS28-ESR $($ mean $\pm S D)$ & $3.9 \pm 1.5$ & $3.8 \pm 1.4$ & $3.6 \pm 1.4$ & $3.4 \pm 1.1$ & $3.4 \pm 1.2$ & $3.4 \pm 1.3$ & $3.5 \pm 1.4$ & $3.4 \pm 1.3$ & $3.4 \pm 1.3$ & $3.5 \pm 1.3$ \\
\hline Low activity, DAS28-ESR<3.2 (\%) & 34.6 & 37.6 & 40.4 & 42.7 & 46.5 & 49.1 & 47.3 & 48.4 & 46.5 & 46.3 \\
\hline Poor global health* $(\%)$ & 24.3 & 24.2 & 24.8 & 21.4 & 21.7 & 20.7 & 21.9 & 21.6 & 21.9 & 19.8 \\
\hline Severe pain* $(\%)$ & 26.3 & 26.5 & 26.6 & 26.0 & 25.4 & 23.2 & 26.6 & 24.9 & 25.0 & 20.4 \\
\hline \multicolumn{11}{|l|}{ Function (\%) } \\
\hline $\mathrm{HAQ} \leq 0.5$ & 13.2 & 13.2 & 13.0 & 12.6 & 12.3 & 13.8 & 13.8 & 13.9 & 15.0 & 17.0 \\
\hline $\mathrm{HAQ}>0.5-1$ & 31.5 & 33.9 & 32.0 & 32.1 & 31.6 & 32.0 & 33.0 & 31.8 & 30.9 & 31.6 \\
\hline $\mathrm{HAQ}>1-2$ & 39.1 & 38.1 & 39.1 & 39.5 & 40.8 & 39.4 & 36.6 & 36.1 & 37.1 & 35.8 \\
\hline $\mathrm{HAQ}>2-3$ & 16.2 & 14.8 & 15.9 & 15.7 & 15.4 & 14.8 & 16.6 & 18.2 & 17.0 & 15.6 \\
\hline \multicolumn{11}{|l|}{ Age $18-64$ years } \\
\hline Cases (n) & 2088 & 2169 & 2172 & 1585 & 1621 & 1614 & 1508 & 1368 & 1549 & 1631 \\
\hline Male (\%) & 18.6 & 18.3 & 19.0 & 21.1 & 22.0 & 22.8 & 23.1 & 22.1 & 23.0 & 21.8 \\
\hline Age $($ mean $\pm S D)$ & $53.2 \pm 9.4$ & $53.2 \pm 9.4$ & $53.0 \pm 9.3$ & $52.0 \pm 9.8$ & $51.8 \pm 9.7$ & $51.8 \pm 9.7$ & $52.0 \pm 9.5$ & $51.4 \pm 9.4$ & $51.8 \pm 9.5$ & $52.2 \pm 9.2$ \\
\hline Disease duration (median) & 7.7 & 7.8 & 7.8 & 7.3 & 7.8 & 8.1 & 7.8 & 8.5 & 8.8 & 8.8 \\
\hline DAS28-ESR $($ mean $\pm S D)$ & $3.8 \pm 1.5$ & $3.7 \pm 1.5$ & $3.6 \pm 1.4$ & $3.4 \pm 1.2$ & $3.4 \pm 1.2$ & $3.3 \pm 1.3$ & $3.4 \pm 1.4$ & $3.4 \pm 1.4$ & $3.3 \pm 1.4$ & $3.4 \pm 1.4$ \\
\hline Low activity, DAS28-ESR<3.2 (\%) & 36.2 & 39.8 & 41.8 & 43.7 & 47.2 & 49.5 & 47.4 & 49.3 & 50.1 & 47.8 \\
\hline Poor global health* (\%) & 24.1 & 24.4 & 23.5 & 21.8 & 20.9 & 21.8 & 22.5 & 20.5 & 21.1 & 19.7 \\
\hline Severe pain* $(\%)$ & 27.2 & 26.2 & 25.9 & 26.5 & 25.3 & 24.2 & 28.5 & 25.6 & 25.1 & 21.5 \\
\hline \multicolumn{11}{|l|}{ Function (\%) } \\
\hline $\mathrm{HAQ} \leq 0.5$ & 15.5 & 15.3 & 15.9 & 15.4 & 15.6 & 16.9 & 17.1 & 17.7 & 20.1 & 21.6 \\
\hline $\mathrm{HAQ}>0.5-1$ & 33.0 & 34.7 & 33.4 & 34.9 & 33.6 & 33.0 & 35.0 & 35.0 & 31.5 & 32.6 \\
\hline $\mathrm{HAQ}>1-2$ & 37.7 & 37.7 & 37.8 & 37.9 & 39.3 & 38.6 & 34.5 & 33.1 & 35.9 & 33.6 \\
\hline$H A Q>2-3$ & 13.8 & 12.3 & 12.9 & 11.9 & 11.4 & 11.6 & 13.4 & 14.2 & 12.5 & 12.2 \\
\hline Employed (\%) & 39.1 & 40.1 & 41.6 & 46.5 & 52.0 & 49.8 & 49.9 & 50.8 & 50.4 & 52.9 \\
\hline $\begin{array}{l}\text { Age-adjusted and sex-adjusted population } \\
\text { employment rate (\%) }\end{array}$ & 50.6 & 51.7 & 52.6 & 57.1 & 59.7 & 61.8 & 63.1 & 65.8 & 66.0 & 67.7 \\
\hline Disability pension (\%) & 24.5 & 22.1 & 23.5 & 24.2 & 23.3 & 21.5 & 20.2 & 22.2 & 22.1 & 20.6 \\
\hline Sick leave (\%) & 29.9 & 34.3 & 36.3 & 33.3 & 29.5 & 28.3 & 31.3 & 30.1 & 36.4 & 33.2 \\
\hline $\begin{array}{l}\text { Duration of sick leave in days } \\
\text { (mean } \pm \text { SD) }\end{array}$ & $59.5 \pm 89.0$ & $44.8 \pm 59.4$ & $63.4 \pm 93.6$ & $47.3 \pm 74.9$ & $46.1 \pm 73.9$ & $44.5 \pm 69.7$ & $51.4 \pm 82.8$ & $42.0 \pm 70.5$ & $40.8 \pm 58.1$ & $46.9 \pm 73.2$ \\
\hline \multicolumn{11}{|l|}{ Age $\geq 65$ years } \\
\hline Cases (n) & 1511 & 1688 & 1847 & 1316 & 1551 & 1687 & 1600 & 1590 & 1871 & 1696 \\
\hline Male (\%) & 24.1 & 23.8 & 23.9 & 26.1 & 26.7 & 25.7 & 26.9 & 27.2 & 27.2 & 26.5 \\
\hline Age $($ mean $\pm S D)$ & $72.3 \pm 5.6$ & $72.4 \pm 5.7$ & $72.4 \pm 5.7$ & $71.9 \pm 5.6$ & $72.1 \pm 5.6$ & $72.2 \pm 5.6$ & $72.5 \pm 5.7$ & $72.9 \pm 5.7$ & $73.4 \pm 5.5$ & $73.7 \pm 5.6$ \\
\hline Disease duration (median) & 8.5 & 8.7 & 9.1 & 9.5 & 9.4 & 10.2 & 10.5 & 11.0 & 11.5 & 11.7 \\
\hline DAS28-ESR $($ mean $\pm S D)$ & $3.9 \pm 1.5$ & $3.8 \pm 1.4$ & $3.7 \pm 1.4$ & $3.5 \pm 1.1$ & $3.5 \pm 1.2$ & $3.4 \pm 1.2$ & $3.5 \pm 1.3$ & $3.5 \pm 1.3$ & $3.5 \pm 1.3$ & $3.5 \pm 1.3$ \\
\hline Low activity, DAS28-ESR<3.2 (\%) & 32.2 & 34.7 & 38.8 & 41.6 & 45.8 & 48.7 & 47.2 & 47.5 & 43.4 & 44.7 \\
\hline Poor global health* $(\%)$ & 24.7 & 23.9 & 26.4 & 20.9 & 22.6 & 19.6 & 21.3 & 22.6 & 22.5 & 19.9 \\
\hline Severe pain* $(\%)$ & 24.9 & 27.0 & 27.5 & 25.4 & 25.5 & 22.1 & 24.7 & 24.3 & 25.0 & 19.4 \\
\hline \multicolumn{11}{|l|}{ Function (\%) } \\
\hline $\mathrm{HAQ} \leq 0.5$ & 9.9 & 10.2 & 9.5 & 9.2 & 8.7 & 10.8 & 10.5 & 10.6 & 10.8 & 12.3 \\
\hline $\mathrm{HAQ}>0.5-1$ & 29.2 & 32.9 & 30.3 & 28.8 & 29.5 & 30.9 & 31.1 & 29.0 & 30.3 & 30.6 \\
\hline $\mathrm{HAQ}>1-2$ & 41.1 & 38.7 & 40.7 & 41.6 & 42.3 & 40.2 & 38.6 & 38.7 & 38.1 & 38.0 \\
\hline$H A Q>2-3$ & 19.7 & 18.2 & 19.5 & 20.3 & 19.4 & 18.0 & 19.7 & 21.6 & 20.8 & 19.1 \\
\hline
\end{tabular}

${ }^{*} \mathrm{~A}$ score of $7-10$ on a numerical rating scale from 0 to 10 .

and a decrease in patients with severe disability (FCA/HCA: $€ 1930 /-€ 343)$.

Only direct costs contribute to the cost calculation for retired patients. Most changes were induced by drug costs, correlating with the level of disability: the increase was $€ 945$ in the group with good functional capacity, $€ 1621$ in patients with mild, $€ 2544$ with moderate, and $€ 4185$ with severe functional disability (figure 3). Inpatient treatment, including hospitalisation and inpatient rehabilitation, led to a reduction in costs of $€ 1382$ between 2002 and 2011 for patients with severe disability, and $€ 741$ for patients with moderate disability. Other treatments, including physiotherapy, imaging, joint replacement surgery and physician visits, remained vastly stable in the two better groups and increased in those with moderate and severe disability $(+€ 403,+€ 545)$. In total, the average annual costs rose by $€ 3347$ for patients with severe disability, by $€ 2206$ with moderate disability, and by $€ 2204$ with mild disability, and by $€ 1114$ for patients with good functional capacity. 
Table 2 Healthcare use from 2002 to 2011

\begin{tabular}{|c|c|c|c|c|c|c|c|c|c|c|}
\hline & 2002 & 2003 & 2004 & 2005 & 2006 & 2007 & 2008 & 2009 & 2010 & 2011 \\
\hline \multicolumn{11}{|l|}{ All patients } \\
\hline Any DMARDs (\%) & 86.3 & 84.9 & 87.3 & 87.1 & 80.8 & 84.5 & 84.4 & 85.5 & 86.0 & 85.8 \\
\hline Synthetic DMARDs (\%) & 84.0 & 81.1 & 82.4 & 79.7 & 72.6 & 77.8 & 77.0 & 76.5 & 77.9 & 76.9 \\
\hline Biologics (\%) & 4.4 & 8.2 & 9.6 & 14.0 & 16.8 & 16.2 & 19.4 & 23.4 & 23.9 & 25.2 \\
\hline Other antirheumatic drugs (\%) & 86.3 & 87.1 & 85.2 & 96.7 & 96.7 & 95.4 & 96.4 & 95.1 & 91.2 & 84.1 \\
\hline Hospitalisation (\%) & 19.6 & 17.2 & 17.6 & 16.9 & 16.2 & 16.8 & 18.2 & 16.7 & 16.9 & 16.3 \\
\hline Duration in days (mean \pm SD) & $20.8 \pm 17.7$ & $21.1 \pm 15.4$ & $20.5 \pm 20.7$ & $18.1 \pm 22.8$ & $15.3 \pm 15.5$ & $16.2 \pm 14.0$ & $16.1 \pm 15.0$ & $14.3 \pm 8.4$ & $14.7 \pm 9.9$ & $13.5 \pm 8.0$ \\
\hline Rehabilitation (\%) & 12.9 & 10.8 & 9.7 & 10.4 & 9.5 & 12.4 & 12.1 & 11.9 & 24.5 & 11.3 \\
\hline Duration in weeks $\left(\right.$ mean $\left.\pm S D^{*}\right)$ & $3.6 \pm 1.2$ & $3.8 \pm 3.1$ & $3.6 \pm 1.8$ & $3.5 \pm 0.2$ & $3.6 \pm 0.2$ & $3.5 \pm 0.2$ & $3.5 \pm 0.2$ & $3.5 \pm 1.8$ & $3.8 \pm 2.5$ & $3.3 \pm 1.7$ \\
\hline Physiotherapy (\%) & 51.2 & 49.5 & 48.4 & 45.9 & 45.9 & 30.6 & 22.0 & 33.4 & 42.6 & 46.2 \\
\hline Joint replacement surgery (\%) & 2.3 & 2.2 & 2.1 & 3.5 & 3.5 & 2.5 & 1.9 & 3.5 & 3.2 & 3.5 \\
\hline Imaging $(\%)$ & 85.1 & 82.7 & 82.5 & 83.0 & 69.9 & 75.8 & 67.3 & 71.3 & 72.4 & 72.5 \\
\hline \multicolumn{11}{|l|}{ Age $18-64$ years } \\
\hline Any DMARDs (\%) & 89.0 & 86.3 & 88.5 & 88.3 & 81.8 & 85.7 & 84.3 & 87.3 & 88.0 & 86.9 \\
\hline Synthetic DMARDs (\%) & 86.5 & 81.7 & 82.7 & 78.6 & 71.6 & 77.4 & 75.5 & 77.5 & 78.8 & 76.6 \\
\hline Biologics (\%) & 5.6 & 10.0 & 11.8 & 18.1 & 21.3 & 20.9 & 24.2 & 29.4 & 31.6 & 31.2 \\
\hline Other antirheumatic drugs (\%) & 85.4 & 85.1 & 83.0 & 95.8 & 95.8 & 93.8 & 95.2 & 93.1 & 88.9 & 79.7 \\
\hline Hospitalisation (\%) & 21.6 & 18.4 & 19.4 & 17.0 & 16.1 & 16.1 & 18.7 & 18.0 & 17.0 & 16.9 \\
\hline Duration in days (mean \pm SD) & $18.9 \pm 15.0$ & $19.2 \pm 13.6$ & $19.4 \pm 21.1$ & $15.5 \pm 13.2$ & $14.4 \pm 11.2$ & $16.2 \pm 17.0$ & $16.4 \pm 18.2$ & $12.9 \pm 7.7$ & $14.1 \pm 9.1$ & $13.7 \pm 9.2$ \\
\hline $\begin{array}{l}\text { Mean duration of hospitalisation in days in the } \\
\text { general population aged } 45-64 \text { years }\end{array}$ & 9.2 & 8.8 & 8.6 & 8.6 & 8.5 & 8.3 & 8.1 & 8.0 & 7.9 & 7.7 \\
\hline Rehabilitation (\%) & 14.4 & 11.1 & 10.7 & 11.4 & 10.0 & 12.6 & 12.3 & 11.7 & 23.5 & 12.3 \\
\hline Duration in weeks (mean \pm SD*) & $3.5 \pm 1.1$ & $4.1 \pm 4.0$ & $3.7 \pm 2.0$ & $3.5 \pm 0.2$ & $3.6 \pm 0.2$ & $3.5 \pm 0.2$ & $3.5 \pm 0.2$ & $3.7 \pm 1.8$ & $3.8 \pm 2.3$ & $3.4 \pm 1.6$ \\
\hline Physiotherapy (\%) & 51.2 & 50.1 & 48.2 & 42.0 & 41.9 & 31.5 & 22.5 & 32.0 & 44.2 & 46.2 \\
\hline Joint replacement surgery (\%) & 2.2 & 1.9 & 1.8 & 2.5 & 2.8 & 1.9 & 0.9 & 1.9 & 2.0 & 2.2 \\
\hline Imaging $(\%)$ & 84.5 & 83.5 & 83.2 & 85.0 & 69.1 & 75.0 & 65.5 & 69.7 & 72.4 & 72.8 \\
\hline \multicolumn{11}{|l|}{ Age $\geq 65$ years } \\
\hline Any DMARDs (\%) & 82.5 & 83.1 & 85.9 & 85.7 & 79.6 & 83.3 & 84.6 & 83.8 & 84.3 & 84.8 \\
\hline Synthetic DMARDs (\%) & 80.6 & 80.3 & 82.1 & 81.1 & 73.7 & 78.2 & 78.5 & 75.7 & 77.2 & 77.1 \\
\hline Biologics $(\%)$ & 2.8 & 6.0 & 7.0 & 9.0 & 11.7 & 11.7 & 14.7 & 18.0 & 17.5 & 19.2 \\
\hline Other antirheumatic drugs (\%) & 87.5 & 89.6 & 87.9 & 97.4 & 97.4 & 96.9 & 97.4 & 96.8 & 93.2 & 88.5 \\
\hline Hospitalisation (\%) & 16.8 & 15.5 & 15.4 & 16.7 & 16.3 & 17.6 & 17.6 & 15.4 & 16.8 & 15.7 \\
\hline duration in days (mean \pm SD) & $24.6 \pm 21.9$ & $24.1 \pm 17.6$ & $22.1 \pm 20.2$ & $21.9 \pm 31.3$ & $16.3 \pm 19.3$ & $16.1 \pm 9.9$ & $15.8 \pm 9.9$ & $15.9 \pm 8.9$ & $15.2 \pm 10.6$ & $13.2 \pm 6.2$ \\
\hline $\begin{array}{l}\text { Mean duration of hospitalisation in days in the } \\
\text { general population aged } \geq 65 \text { years }\end{array}$ & 11.4 & 10.8 & 10.4 & 10.3 & 10.0 & 9.9 & 9.6 & 9.4 & 9.2 & 9.0 \\
\hline Rehabilitation (\%) & 10.6 & 10.3 & 8.4 & 9.3 & 8.8 & 12.2 & 11.8 & 12.1 & 25.4 & 10.1 \\
\hline Duration in weeks (mean $\pm S D^{\star}$ ) & $3.7 \pm 1.4$ & $3.3 \pm 0.9$ & $3.4 \pm 1.3$ & $3.5 \pm 0.2$ & $3.6 \pm 0.2$ & $3.6 \pm 0.3$ & $3.5 \pm 0.2$ & $3.3 \pm 1.8$ & $3.8 \pm 2.8$ & $3.2 \pm 1.9$ \\
\hline Physiotherapy (\%) & 49.0 & 48.9 & 46.6 & 50.7 & 50.3 & 29.7 & 21.5 & 34.8 & 41.3 & 46.3 \\
\hline Joint replacement surgery (\%) & 2.4 & 2.6 & 2.5 & 4.4 & 4.2 & 2.9 & 2.9 & 4.9 & 4.2 & 4.7 \\
\hline Imaging $(\%)$ & 85.9 & 81.8 & 81.8 & 80.8 & 70.7 & 76.5 & 68.9 & 72.7 & 72.4 & 72.2 \\
\hline
\end{tabular}

\section{DISCUSSION}

There was a continuous increase in the average annual costs for patients with RA treated by German rheumatologists between 2002 and 2011, driven by the growing use of biologic agents. However, the increase was partly offset by decreasing costs for inpatient treatment, sick leave and work disability. Improvements in the employment situation seen in our data were similar to the population trend.

Our study has included direct and indirect costs only, not considering intangible costs related to quality of life. Constant improvements in physical function, pain, disease activity or global health over time suggest that a full economic evaluation including quality-adjusted lifeyear (QALY) considerations could further explore the trade-off between rising costs and improvements in quality of life, though these intangible costs are already partly reflected by savings in indirect cost domains. ${ }^{24}$
When taking disability into account, the doubled direct costs in patients with moderate or mild disability were not fully reflected in the total cost due to a shift in the patient case mix over time. For instance, in 2011, 22\% of the patients were in a good functional status, the group with the lowest costs, compared to $15 \%$ in 2002 .

The figures in our study correspond well with data from other Western European countries and Northern America: in a systematic review of 26 studies published up to 2007, Franke et $a l^{4}$ found a mean of $€ 4170$ annual healthcare costs for RA (IQR: 2756-4561). This is in line with our data for the first years of observation, while for the later years not covered by the review, we found higher direct costs.

The direct costs strongly depend on the prizes for drugs. In Norway, average annual drug costs in RA patients were $€ 2249$ 
Table 3 Average direct and indirect annual costs (in $€$ ), age 18-64 years, and average direct annual costs (in $€$ ), age $\geq 65$ years; calculated with current prices

\begin{tabular}{|c|c|c|c|c|c|c|c|c|c|c|}
\hline & 2002 & 2003 & 2004 & 2005 & 2006 & 2007 & 2008 & 2009 & 2010 & 2011 \\
\hline \multicolumn{11}{|l|}{ Age $18-64$ years } \\
\hline Cases (n) & 2088 & 2169 & 2172 & 1585 & 1621 & 1614 & 1508 & 1368 & 1549 & 1631 \\
\hline Drugs & 2522 & 3576 & 3631 & 4018 & 4368 & 4572 & 4890 & 5971 & 6142 & 6089 \\
\hline Biologic DMARDs & 1491 & 2578 & 2662 & 3217 & 3524 & 3560 & 3938 & 4890 & 5013 & 5089 \\
\hline Synthetic DMARDs & 661 & 626 & 584 & 431 & 483 & 619 & 598 & 656 & 710 & 608 \\
\hline Other antirheumatic drugs & 369 & 371 & 386 & 371 & 362 & 393 & 354 & 425 & 420 & 392 \\
\hline Hospitalisation & 1429 & 1293 & 1487 & 1070 & 984 & 1142 & 1411 & 1145 & 1230 & 1237 \\
\hline Rehabilitation & 330 & 299 & 261 & 223 & 178 & 157 & 195 & 186 & 196 & 223 \\
\hline Other treatment costs & 633 & 594 & 598 & 642 & 671 & 601 & 505 & 473 & 624 & 657 \\
\hline Physician visits & 330 & 314 & 323 & 330 & 336 & 341 & 351 & 221 & 349 & 351 \\
\hline Joint replacement surgery & 168 & 149 & 141 & 197 & 227 & 160 & 73 & 161 & 171 & 189 \\
\hline Physiotherapy & 86 & 84 & 86 & 64 & 60 & 50 & 33 & 44 & 55 & 61 \\
\hline Imaging & 48 & 47 & 48 & 50 & 48 & 49 & 48 & 47 & 49 & 55 \\
\hline Total direct costs & 4914 & 5762 & 5978 & 5953 & 6201 & 6471 & 7001 & 7775 & 8191 & 8206 \\
\hline Sick leave & 1707 & 1499 & 2301 & 1423 & 1249 & 1149 & 1529 & 1195 & 1252 & 1525 \\
\hline \multicolumn{11}{|l|}{ Friction cost approach } \\
\hline Permanent work disability & 1680 & 1311 & 1449 & 1455 & 1383 & 1421 & 1416 & 1562 & 1569 & 1552 \\
\hline Total indirect costs & 3388 & 2810 & 3750 & 2878 & 2632 & 2570 & 2946 & 2757 & 2821 & 3077 \\
\hline Total costs & 8302 & 8572 & 9728 & 8831 & 8833 & 9041 & 9947 & 10532 & 11012 & 11283 \\
\hline \multicolumn{11}{|l|}{ Human capital approach } \\
\hline Permanent work disability & 8902 & 8017 & 8712 & 8551 & 8013 & 8064 & 7902 & 8566 & 8459 & 8229 \\
\hline Total indirect costs & 10609 & 9515 & 11013 & 9974 & 9262 & 9213 & 9432 & 9761 & 9711 & 9754 \\
\hline Total costs & 15523 & 15277 & 16991 & 15927 & 15463 & 15684 & 16433 & 17536 & 17902 & 17960 \\
\hline \multicolumn{11}{|l|}{ Age $\geq 65$ years } \\
\hline Cases (n) & 1511 & 1688 & 1847 & 1316 & 1551 & 1687 & 1600 & 1590 & 1871 & 1696 \\
\hline Drugs & 1765 & 2500 & 2548 & 2412 & 2687 & 2975 & 3349 & 3904 & 3767 & 4047 \\
\hline Biologic DMARDs & 767 & 1517 & 1584 & 1648 & 1902 & 2066 & 2403 & 2947 & 2737 & 3032 \\
\hline Synthetic DMARDs & 601 & 572 & 538 & 380 & 412 & 532 & 575 & 532 & 590 & 583 \\
\hline Other antirheumatic drugs & 397 & 411 & 426 & 384 & 374 & 376 & 371 & 425 & 440 & 432 \\
\hline Hospitalisation & 1447 & 1392 & 1353 & 1439 & 1115 & 1238 & 1281 & 1201 & 1304 & 1126 \\
\hline Rehabilitation & 251 & 230 & 185 & 153 & 148 & 151 & 144 & 153 & 168 & 143 \\
\hline Other treatment costs & 637 & 626 & 638 & 842 & 827 & 699 & 687 & 861 & 840 & 904 \\
\hline Physician visits & 323 & 307 & 322 & 353 & 361 & 362 & 367 & 349 & 376 & 378 \\
\hline Joint replacement surgery & 188 & 198 & 193 & 352 & 337 & 241 & 243 & 419 & 361 & 417 \\
\hline Physiotherapy & 79 & 75 & 76 & 84 & 76 & 43 & 30 & 45 & 52 & 61 \\
\hline Imaging & 48 & 46 & 47 & 53 & 53 & 53 & 47 & 48 & 50 & 48 \\
\hline Total (direct) costs & 4100 & 4748 & 4724 & 4846 & 4777 & 5063 & 5462 & 6120 & 6079 & 6221 \\
\hline
\end{tabular}

in a register with $16 \%$ prescription of biologic DMARDs, based upon prizes from $2010 .{ }^{6}$ In 2007 , when we also had $16 \%$ biologics, our average annual drug costs were $€ 3756$.

Boonen and Severens ${ }^{26}$ reported that for paid productivity loss the weighted mean sick leave costs were $€ 2770$ per patient, and productivity costs were $€ 8452$ using the HCA, and $€ 1441$ using the FCA. Our costs are lower for sick leave (€1707 in 2002 and $€ 1525$ in 2011) and comparable for permanent work disability. In a Swedish study, ${ }^{27}$ for inpatients aged 19-64 years, costs associated with sick leave and disability pension attributable to RA were $€ 9000$ in 2007 , which closely corresponds to our indirect costs in 2007 of $€ 9213$ with the HCA.

The study has strengths and limitations: A strength is that we were able to observe changes for cost components in large patient samples gathered within the same study and in the same rheumatological units over 10 years. Clinical, patientderived as well as resource-utilisation data were available. A limitation is that we probably underestimated 12-monthsrelated components due to memory bias but, more importantly, overestimated drug costs: We had to use the published price list not accounting for discount contracts between health insurances and pharmaceutical companies, as each insurance fund has separate, confidential contracts. Individual discount rates can be up to $30 \%$. Compared to German rheumatology in general, we overestimated the cost for biologic agents, since $50 \%$ of our units were hospitals which had higher prescriptions of biologics in our data (29\% compared to $16 \%$ in practices in 2011), whereas $81 \%$ of German rheumatologists work in private practices. ${ }^{28}$ According to a population survey, $64 \%$ of RA patients in Germany were in rheumatological care in $2008 .^{29}$ Since biologic agents are prescribed nearly exclusively by rheumatologists, when generalising to all RA patients, the costs for biologic agents per patient, therefore, have to be reduced by about one-third.

In summary, our data show that despite considerably increased drug costs, the overall costs of RA in patients treated by German rheumatologists did not change substantially. This might have been even more pronounced if we had been able to 


\section{Clinical and epidemiological research}

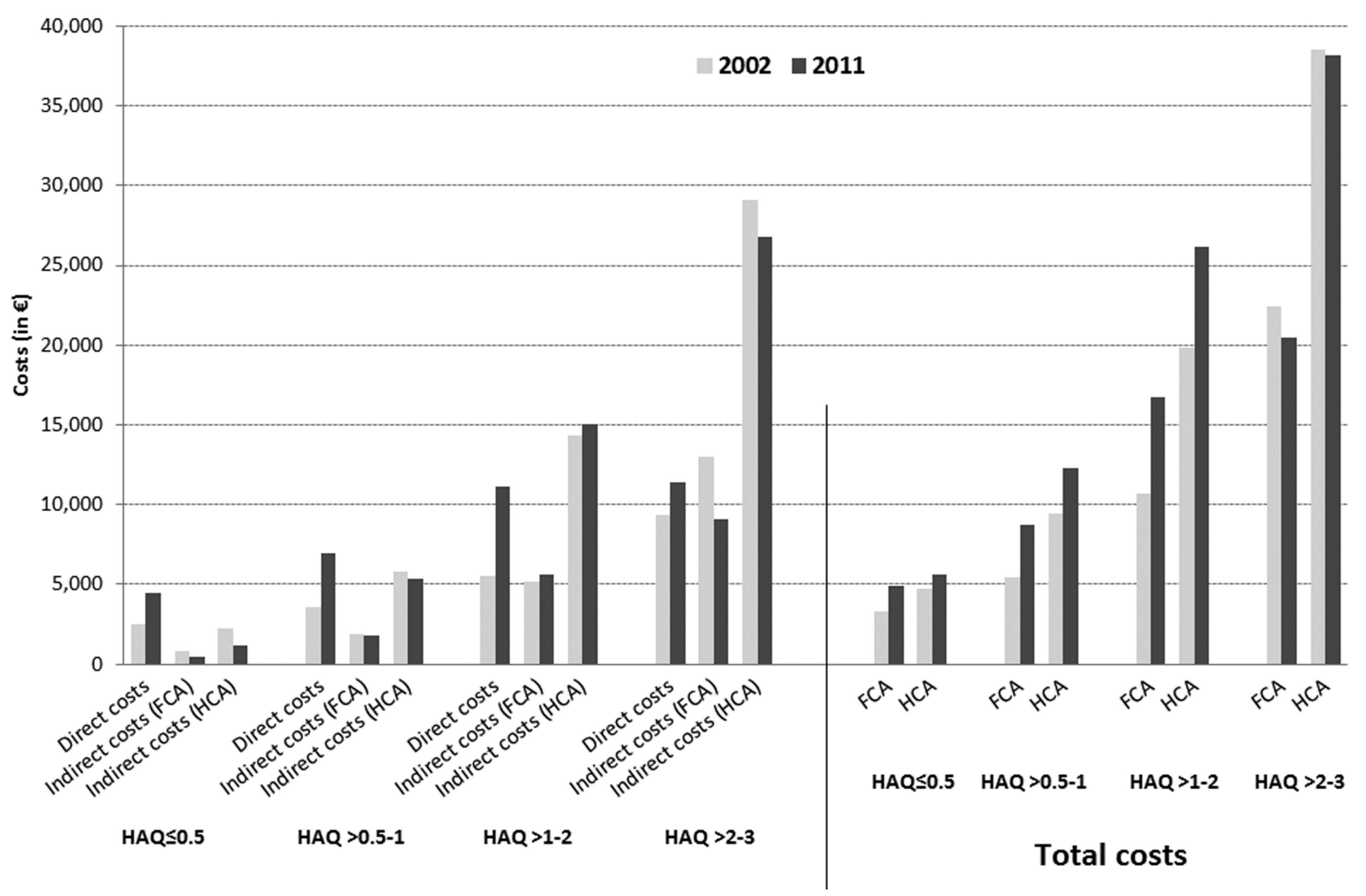

Figure 2 Comparison of the average annual costs in 2002 and 2011 for patients aged 18-64 years by functional capacity; calculated with current prices. HCA, human capital approach; FCA, friction cost approach.

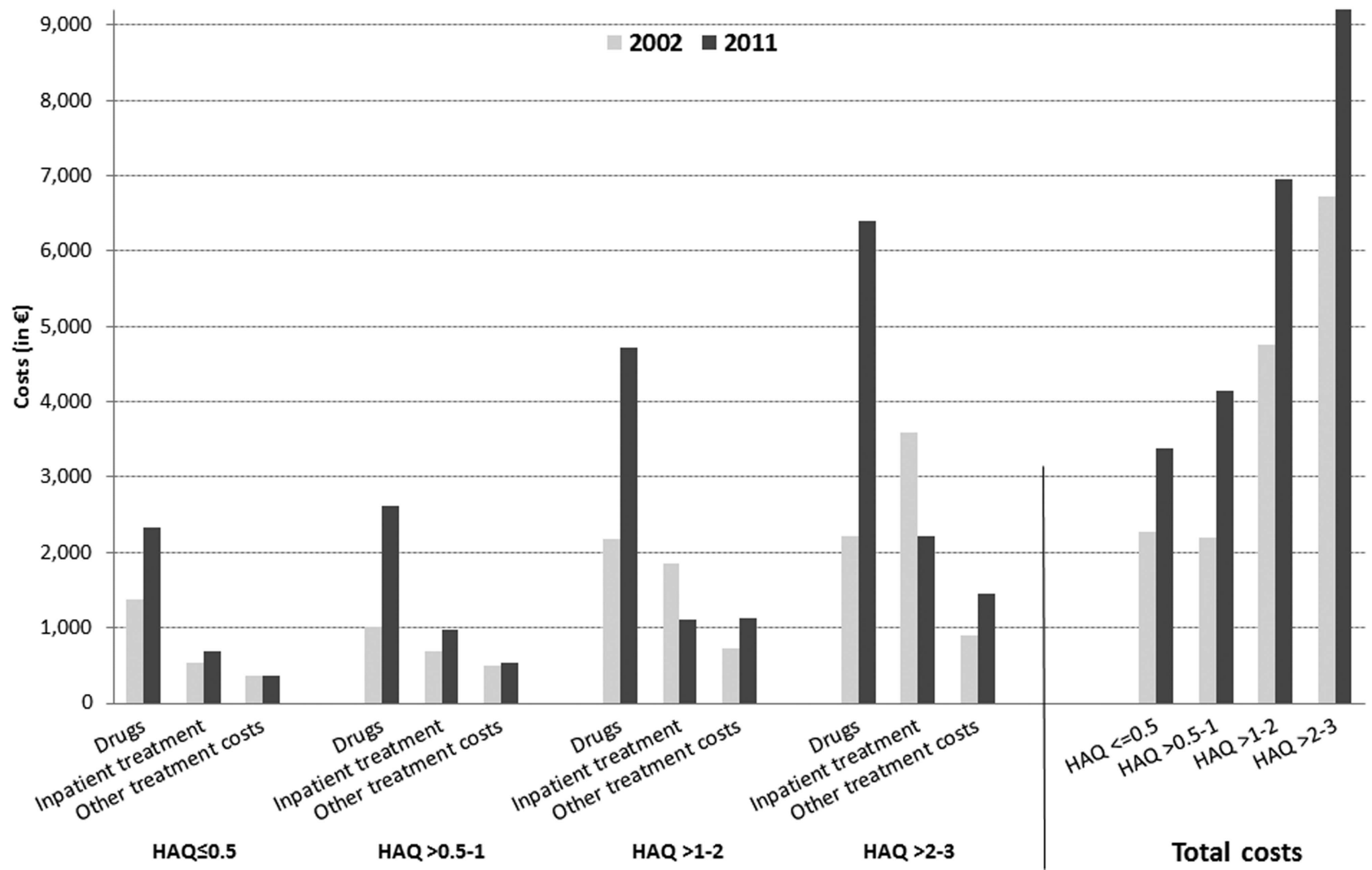

Figure 3 Comparison of the average annual direct costs in 2002 and 2011 of patients aged $\geq 65$ years by functional capacity; calculated with current prices (other treatment costs include physician visits, joint replacement surgery, physiotherapy, and imaging). 
subtract price discounts. The data also show that the rise in drug costs driven by biologic agents has been at a plateau since 2009. This is supported by preliminary analyses of our database for 2012, which reveal prescription rates of biologic agents at the same level as 2011 (data not shown). Given the trend to earlier treatment initiation, improved treatment strategies with conventional DMARDs, including triple therapy, ${ }^{30}$ and overall better outcomes, ${ }^{10}$ we do not expect further large cost increases for the treatment of RA in Germany in the next few years.

Acknowledgements The authors acknowledge the invaluable contributions and the enthusiasm of all participating consultant rheumatologists who contributed data of their patients with inflammatory rheumatic diseases to the National Database since 1993. In particular, the authors would like to acknowledge the significant contributions of R Alten (Berlin), M Aringer (Dresden), M Backhaus (Berlin), H Burkhardt (Frankfurt/Main), R de la Camp (Erlangen), T Eidner (Jena), K Fischer (Greifswald), K Karberg (Berlin), A Krause (Berlin), W Ochs (Bayreuth), HH Peter (Freiburg), J Richter (Düsseldorf), S Späthling-Mestekemper (München) and S Wassenberg (Ratingen).

Contributors Conception and design, analysis and interpretation of data: $\mathrm{DH}, \mathrm{TM}$, $\mathrm{SB}, \mathrm{AP}, \mathrm{AZ}$. Acquisition of data: UvH, IK, GH. Drafting the article: $\mathrm{DH}, \mathrm{TM}, \mathrm{AZ}$. Revising it critically for important intellectual content: UvH, IK, GH, SB, AP. Final approval of the version published: DH, TM, UvH, IK, GH, SB, AP, AZ.

Funding The Federal Ministry of Research and Education funded the National Database from 1999 to 2007 (grant 01GI/9944/3). Since 2007, the database has been funded through unconditional grants from the German Collaborative Arthritis Centres and a consortium of 11 pharmaceutical companies. The principal investigators and their team had full academic freedom in study design and conduct, data analysis and publication of results.

Competing interests None.

Patient consent Obtained.

Ethics approval Ethics committee of the Charité Universitätsmedizin Berlin (Charité University Hospital).

Provenance and peer review Not commissioned; externally peer reviewed.

Data sharing statement The National Database of the German Collaborative Arthritis Centres is exclusively accessible by the Epidemiology Unit, German Rheumatism Research Centre Berlin, Germany.

Open Access This is an Open Access article distributed in accordance with the Creative Commons Attribution Non Commercial (CC BY-NC 3.0) license, which permits others to distribute, remix, adapt, build upon this work non-commercially, and license their derivative works on different terms, provided the original work is properly cited and the use is non-commercial. See: http://creativecommons.org/ licenses/by-nc/3.0/

\section{REFERENCES}

1 Symmons D, Turner G, Webb R, et al. The prevalence of rheumatoid arthritis in the United Kingdom: new estimates for a new century. Rheumatology (Oxford) 2002:41:793-800.

2 Gabriel SE, Michaud K. Epidemiological studies in incidence, prevalence, mortality, and comorbidity of the rheumatic diseases. Arthritis Res Ther 2009;11:229.

3 Guillemin F, Saraux A, Guggenbuhl P, et al. Prevalence of rheumatoid arthritis in France: 2001. Ann Rheum Dis 2005;64:1427-30.

4 Franke LC, Ament AJ, van de Laar MA, et al. Cost-of-illness of rheumatoid arthritis and ankylosing spondylitis. Clin Exp Rheumatol 2009;27:S118-23.

5 Kawatkar AA, Jacobsen SJ, Levy GD, et al. Direct medical expenditure associated with rheumatoid arthritis in a nationally representative sample from the medical expenditure panel survey. Arthritis Care Res (Hoboken) 2012;64:1649-56.

6 Kvamme MK, Lie E, Kvien TK, et al. Two-year direct and indirect costs for patients with inflammatory rheumatic joint diseases: data from real-life follow-up of patients in the NOR-DMARD registry. Rheumatology (Oxford) 2012;51:1618-27.
7 Huscher D, Merkesdal S, Thiele K, et al. Cost of illness in rheumatoid arthritis, ankylosing spondylitis, psoriatic arthritis and systemic lupus erythematosus in Germany. Ann Rheum Dis 2006;65:1175-83.

8 Modena V, Bianchi G, Roccatello D. Cost-effectiveness of biologic treatment for rheumatoid arthritis in clinical practice: An achievable target? Autoimmun Rev 2013:12:835-8

9 Fautrel B, Verstappen SM, Boonen A. Economic consequences and potential benefits. Best Pract Res Clin Rheumatol 2011:25:607-24.

10 Ziegler S, Huscher D, Karberg K, et al. Trends in treatment and outcomes of rheumatoid arthritis in Germany 1997-2007: results from the National Database of the German Collaborative Arthritis Centres. Ann Rheum Dis 2010;69:1803-8.

11 Hagel S, Petersson IF, Bremander A, et al. Trends in the first decade of 21st century healthcare utilisation in a rheumatoid arthritis cohort compared with the general population. Ann Rheum Dis 2013;72:1212-16.

12 Ter Wee MM, Lems WF, Usan $\mathrm{H}$, et al. The effect of biological agents on work participation in rheumatoid arthritis patients: a systematic review. Ann Rheum Dis 2012;71:161-71.

13 Furneri G, Mantovani LG, Belisari A, et al. Systematic literature review on economic implications and pharmacoeconomic issues of rheumatoid arthritis. Clin Exp Rheumatol 2012;30:572-84.

14 Jacobs P, Bissonnette R, Guenther LC. Socioeconomic burden of immune-mediated inflammatory diseases--focusing on work productivity and disability. I Rheumatol Suppl 2011;88:55-61.

15 Arnett FC, Edworthy SM, Bloch DA, et al. The American Rheumatism Association 1987 revised criteria for the classification of rheumatoid arthritis. Arthritis Rheum 1988:31:315-24

16 Lautenschlaeger J, Mau W, Kohlmann T, et al. [Comparative evaluation of a German version of the Health Assessment Questionnaire and the Hannover Functional Capacity Questionnaire] German. Z Rheumatol 1997;56:144-55.

17 Lauer-Taxe. http://www.lauer-taxe-online.de/ Published Online First: May 2011.

18 Statistik der Deutschen Rentenversicherung 1995-2009. Statistik-CD. Deutsche Rentenversicherung Bund, ed. (accessed Mar 2011).

19 Kostennachweis der Krankenhäuser. http://www.gbe-bund.de/gbe10/owards.prc show_pdf?p_id=13572\&p_sprache=d Published Online First: February 2011.

20 Grunddaten der Krankenhäuser. http://www.destatis.de/jetspeed/portal/cms/Sites/ destatis/Internet/DE/Content/Publikationen/Fachveroeffentlichungen/Gesundheit/ Krankenhaeuser/GrunddatenKrankenhaeuser2120611097004, property=file.pdf Published Online First: March 2011

21 Graf von der Schulenburg JM, Greiner W, Jost F, et al. German recommendations on health economic evaluation: third and updated version of the Hanover Consensus. Value Health 2008;11:539-44.

22 Statistisches Jahrbuch 2011. Für die Bundesrepublik Deutschland. Federal Statistical Office: Wiesbaden, 2012.

23 Zhang W, Anis AH. The economic burden of rheumatoid arthritis: beyond health care costs. Clin Rheumatol 2011;30(Suppl 1):S25-32.

24 Zhang W, Chiu JA, Bansback N, et al. An update on the measurement of productivity losses due to rheumatoid diseases. Best Pract Res Clin Rheumatol 2012;26:585-97.

25 Noll S, Heckmann M, Rebien M. Erscheinungsformen und Ausmaß ungedeckter Arbeitskräftenachfrage in der Verlaufsperspektive. Nürnberg: IAB, 2009. Report No.: 07/2009.

26 Boonen A, Severens JL. The burden of illness of rheumatoid arthritis. Clin Rheumatol 2011:30(Suppl 1):S3-8.

27 Neovius M, Simard JF, Askling J. How large are the productivity losses in contemporary patients with RA, and how soon in relation to diagnosis do they develop? Ann Rheum Dis 2011:70:1010-15.

28 Kopetsch T. Altersstruktur- und Arztzahlentwicklung in Deutschland unter besonderer Berücksichtigung der Rheumatologen. http://www.rheumaakademie.de/ fileadmin/media/Kongress/BDRh/2013/Kopetsch_Thomas_Aktueller_Stand_der_ rheumatologischen_Versorgung.pdf Published Online First: April 2013.

29 Westhoff $G$, Schneider M, Raspe $H$, et al. Advance and unmet need of health care for patients with rheumatoid arthritis in the German population-results from the German Rheumatoid Arthritis Population Survey (GRAPS). Rheumatology (Oxford) 2009:48:650-7.

30 Sokka T, Haugeberg G, Asikainen J, et al. Similar clinical outcomes in rheumatoid arthritis with more versus less expensive treatment strategies. Observational data from two rheumatology clinics. Clin Exp Rheumatol 2013;31:409-14. 